\section{PLANNING AHEAD}

MPL - What does it mean? At the end of some entries for companies providing products and services is an "MPL". This means "Main Product Line" and gives you an at-a-glance indication of the sort of products the company specialises in.
Milton Consultants Ltd 14-15 Granby Court

Weymouth

Dorset

DT4 9XB

Tel: 01305785108

MPL: incontinence aids

\section{CARRYCHAIR}

6 Hilton Drive

Prestwich

Manchester

Greater Manchester

M25 8NN

Tel: 01617734803

Carrychair is a most effective device designed by an Occupational Therapist. It carries a folding wheelchair outside a vehicle, which virtually eliminates the struggle and strain normally associated with getting a wheelchair into the boot of a car. It

requires no maintenance, is easy to use, saves bootspace and, most importantly, reduces strenuous lifting, thus minimising back strain. Carrychair fits onto a conventional towing bracket or a tow hitch (not supplied) and can be kept in the boot when not in use.

Carrychair is

proving to be a boon to users and carers alike.

RUD Chains Ltd

Units 10-12

John Wilson Business Park

Thanet Way

Whitstable

Kent

CT5 3QT

Tel: 01227276611

Age Concern England

Astral House

1268 London Road

London

SW16 4ER

Tel: 01816798000

MPL: information and advice
Resources for Severe Learning Difficulties

The Consortium

Jack Tizzard School

Finlay Street

London

SW6 6HB

Tel: 01716103755

MPL: educational resources

\section{Innovations}

NSP House

211 Lower Richmond Road

Richmond

Surrey

TW9 4AN

Tel: 01818789111

See display advertisement in Cars and adaptations section.

Paladon Limited

Unit 18

Central City Industrial Estate Red Lane

Coventry

West Midlands

CV6 5RY

Tel: 01203638686

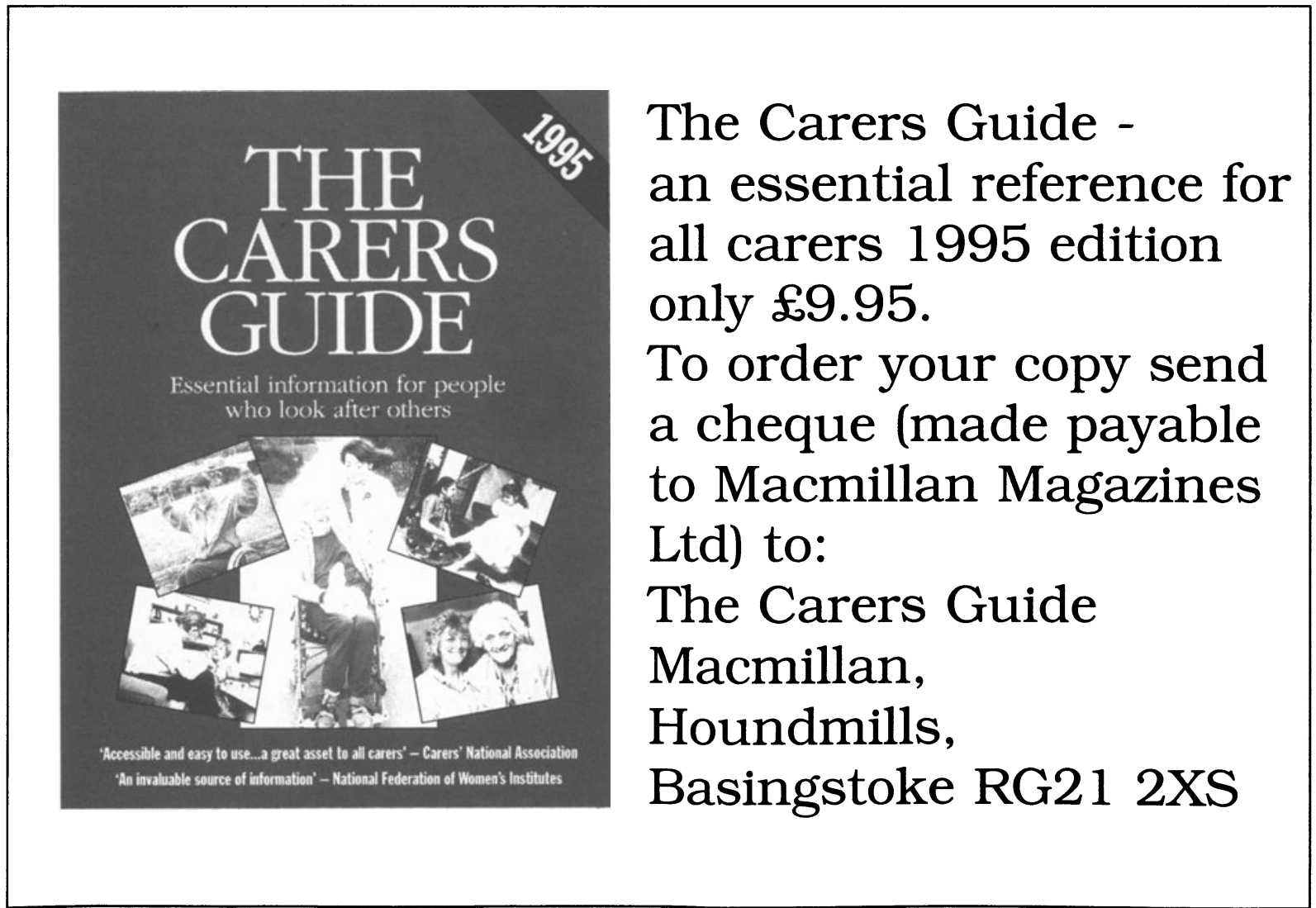

